\title{
What factors affect physicians' decisions to use an e-health care system?
}

\author{
Hung-Yu Yang ${ }^{1}$, Ming-Jye Wang ${ }^{2^{*}}$ \\ ${ }^{1}$ Institute of Healthcare Management, Yuanpei University, Hsin-Chu, Taiwan \\ ${ }^{2}$ National Taiwan University Hospital Hsin-Chu Branch, Hsin-Chu, Taiwan; *Corresponding Author: jye9129@gmail.com
}

Received 27 August 2012; revised 28 September 2012; accepted 7 October 2012

\begin{abstract}
Prior studies have not explored physician's attitudes toward, and behavior and willingness to accept an e-health care system. However, physicians can induce demand for their services. The development of the high-tech asthma care mobile service (ACMS) in Taiwan provided a means of exploring key factors in a physician's choice of using an ACMS. The study was based on the technology acceptance model (TAM) and integrated "subjective norm," "innovativeness," and "managerial support" to understand and predict physicians' attitudes and behavioral intentions toward adopting high-tech healthcare systems such as the ACMS. Of 700 questionnaires distributed to physicians with experience using ACMS, 504 completed returns were received (a $72 \%$ response rate). The data were analyzed using the structural equation modeling (SEM) method. The results of the study showed that the model selected to explain and predict utilization of the ACMS had high explanatory power and was a good-fit model. The most critical factor that affected behavioral intentions related to ACMS was user attitude, followed by perceived usefulness, managerial support, subjective norm, perceived ease of use, and innovativeness.
\end{abstract}

Keywords: E-Mobile; Patient Monitoring; Physicians' Decision

\section{INTRODUCTION}

Asthma care mobile service (ACMS), which uses a mobile telephone-based system, is part of the Taiwanese government's "Challenge 2008 National Development Plan," and involves a care platform for patients with asthma. In developing the program, the National Center for High-Performance Computing (NCHC) integrated components from the healthcare industry, the information systems industry, and the communication industry (Chunghwa Telecom Co., Ltd., Taiwan) to provide real-time self-measurement and management for asthma patients. An asthma patient's real-time condition can be monitored using a mobile phone and integrating a global positioning (GPS) system, the Central Weather Bureau's prediction stations, the environmental protection administration's (EPA) Air Quality Monitoring Network, and network platforms and network connections in hospitals [1].

Use of the monitoring system has led to as lower incidence of disease. Mobile telephones are so widely used as an efficient, instant personal communication tool that their function has been expanded from a simple telephone to a microcomputer. In a recent study, a mobiletelephone-based system was used to provide a home endurance exercise training program, and to monitor respiratory symptoms and exercise activity. The result was good compliance and clinical outcomes in patients with moderate-to-severe chronic obstructive pulmonary disease [2]. However, a few drawbacks include the fact that telephone communication is a time-consuming and staffheavy process, and internet access is not always available.

The ACMS operates in the following way: 1) the patient records his breathing, the extent of coughing, quality of sleep, and activities of daily living. He then uses the mobile phone to send the data to NCHC's network platform. 2) The GPS system in the mobile phone can detect the location of the patient and, in real-time, can obtain information on the local climate and air quality. 3) NCHC analyzes and records the information. 4) On the basis of changes in data, physicians can evaluate whether or not a disease crisis occurring if the patient may be at risk. If an asthmatic event does occur, the same mobile system can be used to notify the patient to come to the hospital. 5) The health education center also provides medical information to patients so they can better understand changes in their disease and the doctor's recommendations. Ultimately, patients can recognize changes 
in their own status, with the objective of preventing future asthmatic events.

Since the development of ACMS is still in the initial stages in Taiwan, in a recent study, the high-tech healthcare system for patients was used to explore key factors in the choice of using an ACMS, the results indicated the most critical factor is user attitude, followed by perceived usefulness, subjective norm, perceived ease of use and innovativeness [1]. However, that study did not explore healthcare providers' (physicians') behavior and willingness to accept an e-healthcare system.

Physicians can promote demand for their services [3]. The results of prior studies have shown that physicians play the role of a prescribing agency for patients. Because physicians have the power to prescribe, the situation of supplier-induced demand (SID) tends to be more significant in the medical market. A physician's acceptance of a medication or treatment approach seems to be the crucial factor. One key to the success of high-tech health care systems is an exploration of physicians' behavior and willingness to accept such systems. Therefore, understanding and predicting physicians' acceptance of ACMS in electronic health is very important, and there is a real need to further explore physician's willingness to adopt high-tech healthcare system services.

We designed a study using the ACMS to better understand and predict physicians' acceptance of new technology. The results may help the Taiwanese government to develop the necessary data on high-tech, preventive medical strategies to define an appropriate policy to use in attracting greater participation.

\section{METHODS}

\subsection{Research Model and Hypothesis}

The technology acceptance model (TAM) was developed from the Theory of Reasoned Action and included four constructs, such as perceived easy of use (PEOU), perceived usefulness (PU), attitude toward using (ATT), and behavioral intention to use (BI), is an information systems theory that models how users come to accept and use a technology. The model suggests that when users are presented with a new technology, a number of factors influence their decision about how and when they will use it and has been widely used by information technology researchers to gain a better understanding of information technology adoption and its use by organizations [4]. PEOU is defined as "the degree to which a person believes that using a particular system would be free from effort"; PU is defined as "the degree to which a person believes that using a particular system would enhance his or her job performance", and ATT is defined as "an individual's positive or negative feelings (evaluative affect) about performing the target behavior". While the
TAM has been applied and tested in academic and corporate settings, and has involved students, business managers, clerical and administrative types as subjects, few studies have evaluated the TAM in the healthcare field [5]. To address this, we used the TAM to examine physicians' opinions about and intentions to adopt e-health applications.

Davis [4] indicated that the key factors impacting an individual's willingness to adopt information systems are PU and PEOU. These elements directly affect the user's ATT and BI. Results of other studies also found that an individual with a higher PEOU about technology tended to perceive that the technology was useful and thus had a stronger attitude towards using it $[6,7]$. The higher an individual's PU towards technology, the stronger the ATT [8], and PU also has a direct positive impact on BI $[9,10]$. Based on TAM, if an individual had a positive attitude toward using technology, the BI would be increased [11,12].

Our study proposed the following hypotheses:

Hypothesis 1a: Physicians' PEOU has direct and positive impact on ATT with respect to ACMS.

Hypothesis 1b: Physicians' PEOU has direct and positive impact on PU with respect to ACMS.

Hypothesis 2a: Physicians' $P U$ has direct and positive impact on BI with respect to ACMS.

Hypothesis 2b: Physicians' $\mathrm{PU}$ has direct and positive impact on ATT with respect to ACMS.

Hypothesis 3: Physicians' ATT has direct and positive impact on BI with respect to ACMS.

Another study indicated that the TAM, combined with the "subjective norm" (SN), can also predict acceptance [7,10,12-16]. Schepers and Wetzels [12] found a significant influence of subjective norm on PU and BI. Subjective norms looks at the influence of people in one's social environment on his/her behavioral intentions; the beliefs of people, weighted by the importance one attributes to each of their opinions, will influence one's behavioral intention.

The study proposed the following hypotheses:

Hypothesis 4a: Physicians' SN has direct and positive impact on BI with respect to ACMS.

Hypothesis 4b: Physicians' SN has direct and positive impact on PU with respect to ACMS.

Additionally, Bhatti [6] and Hurt, Joseph, and Cook [17] indicated "innovativeness" is a component of the Innovation Acceptance Model (IAM), which is defined as "the degree to which an individual adopts new ideas relatively earlier than do other members of the social system," and found that innovativeness (IN) will directly affect people's use of virtual learning systems. It will also have a positive direct impact on PEOU, PU using information technology. This study also proposed the following hypotheses: 
Hypothesis 5a: Physicians' IN has direct and positive impact on PEOU with respect to AMCS.

Hypothesis 5b: Physicians' IN has direct and positive impact on PU with respect to AMCS.

Another study indicated that managerial support has direct and positive impact on perceived usefulness and perceived ease of use of the e-Learning system [18].

Hypothesis 6a: Managerial support has direct and positive impact on PEOU with respect to AMCS.

Hypothesis 6b: managerial support has direct and positive impact on PU with respect to AMCS.

The research model (Figure 1) is based on the TAM, and integrates the "subjective norm," "innovativeness," and "managerial support" to understand and predict a physician's attitudes and behavioral intention of using the ACMS. We feel that the results of this study may enhance the Taiwanese government's efforts to develop high-tech, preventive medicine and may also help attract greater participation by the community.

\subsection{Measures of the Constructs and Data Collection}

The survey instrument was constructed by adapting measures used in prior research of perceived ease of use, perceived usefulness, attitude toward use, and behavioral intention in the TAM, as well as by adding subjective norm, innovativeness, and managerial support (MS) measures. All measures were adapted from their original source and were slightly modified to fit the current study. This adaptation was done by first reviewing the original survey instrument and then making minor, appropriate wording modifications, in an effort to clarify the intent of the questions for five pulmonary physicians.

The survey validation review process was performed by experts from the appropriate branch of the healthcare industry. A few recommended word changes were incorporated into the final survey instrument. The operationalization and sources of measurement items in this study are shown in Table 1. All evaluation items employ a five-point Likert scale for measurement, where 1, 2, 3, 4 , and 5 indicate strongly agree, agree, fairly agree, disagree, and strongly disagree, respectively.

Physicians with experience using ACMS were selected as the study subjects. The physicians were affiliated with 32 different hospitals and represented 4 different medical specialties. In this study, 700 physicians were chosen and asked to fill out the questionnaire.

\subsection{Data Analysis Methods}

While the structural equation modeling (SEM) technique was employed to interpret the causal model using LISREL 8.7 (Scientific Software, Inc., Chicago, IL, USA), a confirmatory factor analysis (CFA) was used to
Table 1. Reliability and validity results.

\begin{tabular}{ccccc}
\hline Construct & Items & $\begin{array}{c}\text { Standardized } \\
\text { factor loading }\end{array}$ & $\begin{array}{c}\text { Construct } \\
\text { reliability }\end{array}$ & Cronbach's $\alpha$ \\
\hline SN & 5 & $0.56-0.86$ & 0.86 & 0.85 \\
IN & 3 & $0.62-0.87$ & 0.92 & 0.88 \\
MS & 4 & $0.74-0.89$ & 0.94 & 0.89 \\
PU & 3 & $0.58-0.88$ & 0.81 & 0.80 \\
PEOU & 4 & $0.61-0.80$ & 0.91 & 0.92 \\
ATT & 4 & $0.64-0.82$ & 0.92 & 0.94 \\
BI & 3 & $0.82-0.89$ & 0.95 & 0.95 \\
\hline
\end{tabular}

Key: SN, subjective norm; IN, innovativeness; MS, managerial support; PU, perceived usefulness; PEOU, perceived ease of use; ATT, attitude toward using; $\mathrm{BI}$, behavioral intention to use.

examine the reliability and validity of the measurement model. Each of the impact coefficients was estimated by using the maximum likelihood estimates method, while the model's overall appropriateness of fit was evaluated by using the following seven indicators: chisquare/degrees-of-freedom $\left(\chi^{2} / \mathrm{df}\right)$; goodness-of-fit index (GFI); adjusted goodness-of-fit-index (AGFI); normed fit index (NFI), comparative fit index (CFI); root mean square residual (RMR); and root mean square error of approximation (RMSEA).

\section{RESULTS}

Of the 700 questionnaires distributed to physicians with experience using the asthma care mobile service, 504 completed questionnaires were returned (a $72 \%$ response rate). Of the returns, $73 \%$ were from male physiccians and $27 \%$ were from female physicians. The 504 physicians who responded ranged in age from 29 to 55 years; $36 \%$ were between the ages of 30 to 40 years. Physicians' experience with asthmatic care ranged from 1 to 6 years. At the 0.05 level, the acceptance of ACMS, as measured by the mean score of the technology acceptance model, was found to have no significant relationship between age, practice size, hours per week of personal computer use, and years of experience as a physiccian.

\subsection{Reliability and Validity of Measurement Model}

The goodness-of-fit indexes suggested that the measurement model was a good fit with the data (Table 2). Each latent construct was tested for internal consistency using construct reliability and Cronbach's alpha. As shown in Table 1, the construct reliabilities ranged from 0.81 to 0.95 , while the alpha coefficients ranged from 0.80 to 0.95 , indicating a higher internal consistency of 
Table 2. Fit indices for measurement and structural model.

\begin{tabular}{cccc}
\hline Fit indices & $\begin{array}{c}\text { Recommended } \\
\text { value }\end{array}$ & $\begin{array}{c}\text { Measurement } \\
\text { model }\end{array}$ & $\begin{array}{c}\text { Structural } \\
\text { model }\end{array}$ \\
\hline df & $\leq 3$ & 1.82 & 1.84 \\
GFI & $\geq 0.9$ & 0.88 & 0.88 \\
AGFI & $\geq 0.8$ & 0.86 & 0.86 \\
NFI & $\geq 0.9$ & 0.95 & 0.94 \\
CFI & $\geq 0.9$ & 0.96 & 0.95 \\
RMR & $\leq 0.05$ & 0.032 & 0.047 \\
RMSEA & $\leq 0.1$ & 0.05 & 0.05 \\
\hline
\end{tabular}

Key: $\chi^{2} / \mathrm{df}$, chi-square/degrees-of-freedom; GFI, goodness-of-fit index; AGFI, adjusted goodness-of-fit-index; NFI, normed fit index; CFI, comparative fit index; RMR, root mean square residual; RMSEA, root mean square error of approximation.

measurement indicators $[19,20]$.

Next, convergent validity and discriminant validity were assessed. Convergent validity was supported if the standardized factor loadings were above 0.50 [19]. In Table 1, the standardized factor loadings ranged from 0.56 to 0.89 , and were statistically significant to support the convergent validity. The discriminant validity test was performed by pairing two latent constructs and subjecting them to two models of CFA [21]. All chi-square difference values were statistically significant at $p<0.01$, and the discriminant validity was confirmed.

\subsection{Structural Model}

The SEM technique was used to interpret the causal model (Figure 2). According to the results (see Table 2), the structural model of ACMS was a good fit with the data. Figure 1 demonstrates that there are seven hypotheses that can be supported: PEOU has a significantly positive impact on PU $\left(\lambda=0.51^{* *}\right)$; PU has a signifycantly positive impact on ATT $\left(\lambda=0.83^{*}\right)$; ATT has a significantly positive impact on BI $\left(\lambda=0.86^{*}\right)$; SN has a significantly positive impact on BI $\left(\lambda=0.19^{*}\right)$; SN has a significantly positive impact on $\mathrm{PU}\left(\lambda=0.21^{*}\right)$; IN has a significantly positive impact on $\operatorname{PEOU}\left(\lambda=0.31^{*}\right)$; and MS has a significantly positive impact on PU $\left(\lambda=0.46^{*}\right)$. The $\mathrm{R}^{2}$ value of the model is $0.82(>0.5)$, demonstrating that the ACMS model had favorable explanatory power.

Additionally, we analyzed both direct and indirect effects of the factors on BI. A direct effect is found from the path coefficient between the factor and the BI factor, while an indirect effect represents the effects on BI due to the different factors. The indirect effect is calculated by multiplying the coefficient values of the route. The total effect is calculated by adding the sums of the direct and indirect effects. The results in Table 3 indicate the most critical factor that affects behavioral intention of ACMS is ATT (0.86), followed by PU (0.57), MS

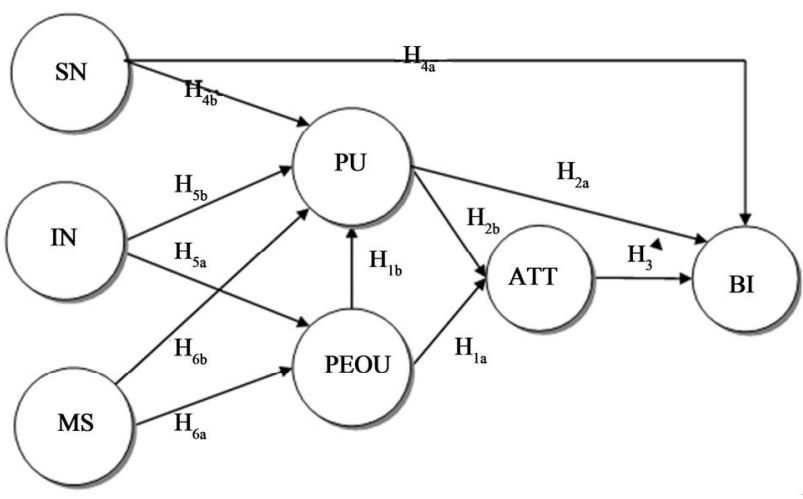

Figure 1. Concept model.

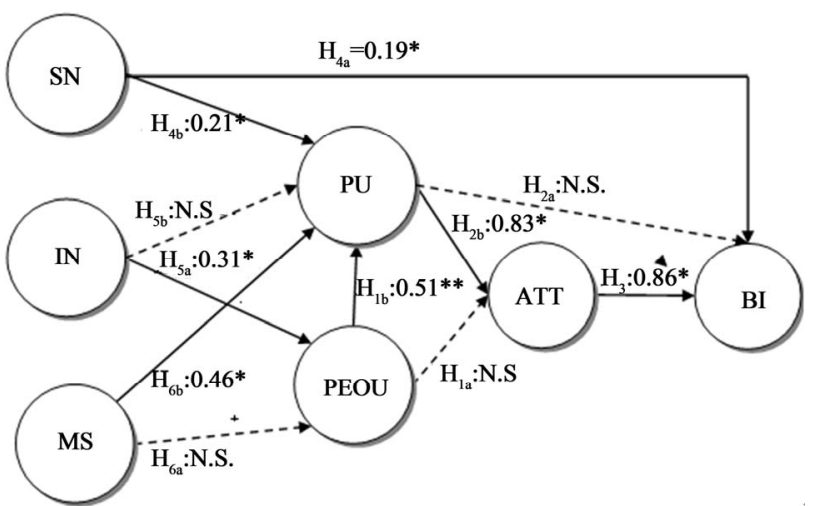

"Path coefficient is significant at the 0.05 level; ${ }^{* *}$ Path coefficient is significant at the 0.01 level; n.s., insignificant at the 0.05 level.

Figure 2. Path diagram of structural equation modeling.

Table 3. Direct and indirect effects for ACMS.

\begin{tabular}{cccc}
\hline Latent variables & $\begin{array}{c}\text { Direct } \\
\text { effect }\end{array}$ & $\begin{array}{c}\text { Indirect } \\
\text { effect }\end{array}$ & $\begin{array}{c}\text { Total effect } \\
\text { (ranking) }\end{array}$ \\
\hline $\mathrm{PEOU} \rightarrow \mathrm{BI}$ & - & 0.38 & $0.38(5)$ \\
$\mathrm{PU} \rightarrow \mathrm{BI}$ & - & 0.57 & $0.57(2)$ \\
$\mathrm{ATT} \rightarrow \mathrm{BI}$ & 0.86 & - & $0.86(1)$ \\
$\mathrm{SN} \rightarrow \mathrm{BI}$ & 0.19 & 0.24 & $0.43(4)$ \\
$\mathrm{IN} \rightarrow \mathrm{BI}$ & - & 0.21 & $0.21(6)$ \\
$\mathrm{MS} \rightarrow \mathrm{BI}$ & - & 0.51 & $0.51(3)$ \\
\hline
\end{tabular}

Key: PEOU, perceived ease of use; PU, perceived usefulness; ATT, attitude toward using; SN, subjective norm; IN, innovativeness; MS, managerial support; BI, behavioral intention to use.

(0.51), SN (0.43), PEOU (0.38), and IN (0.21).

\section{DISCUSSION AND CONCLUSIONS}

The primary results indicated the most critical factor that affects behavioral intention of using ACMS is attitude toward using the devices, followed by perceived usefulness, managerial support, subjective norm, perceived ease of use, and innovativeness. The results are 
consistent with those of relevant past studies. The following suggestions are based on our findings.

ATT and BI with respect to ACMS are positively and significantly associated $[11,12]$. PU has a significantly positive impact on ATT [8], which will affect the attitude of physicians using ACMS. More guarantees to physicians regarding the safety of the mobile system, such as the fact that highly confidential data are protected, the system will "not crash," or users will be able to get an internet signal, will increase the perceived usefulness of the device by physicians.

Subjective norm has a significantly positive impact on behavioral intention and perceived usefulness [7,10], and physicians will be willing to use the system when they think it is helpful and when colleagues encourage them to use it. We propose that hospital association hold regular informative medical lectures and provide medically oriented information to physicians in order to change the subjective norm of physicians.

PEOU has a significantly positive impact on PU [6,7]. Whether or not the ACMS system is easy to operate will affect the physician's ability to determine if it is helpful. We propose that the user interface be made more userfriendly, and a sample model be provided for physicians to use.

Innovativeness has a significantly positive impact on perceived PEOU [22], which means that physicians think the system is easier to use when the innovativeness is higher. Increasing continuing education for physicians in related specialties, such as pulmonary and critical care medicine, pediatrics, family medicine, and internal medicine, may increase physicians' perception of the IN of the system.

Finally, MS has a significantly positive impact on PU [18]. This means that if physicians think the system is successful under managerial support, the top managers will influence the strategies and policies of the healthcare system as well as the support and cooperation from the top managers and the individual departments. In turn, this will be an impetus for development of careful and thoughtful guidelines for participating hospitals, even as top managers aggressively promote acceptance and implementation of the mobile system. All these efforts will have a positive effect on the implementation and adoption of ACMS.

This study was conducted from the perspective of physicians, in order to ascertain the critical factors that affect ACMS users in their inclination toward adopting e-health technology. The model used in the study explained and predicted the utilization of ACMS, with high explanatory power as a good-fit model. It can be applied by researchers, technology developers, and policy makers as relevant.

Results from this study also have interesting implica- tions and recommendations for future research. First, TAM was able to explain over half of the behavioral intention variance $\left(\mathrm{R}^{2}=0.82\right)$. Second, the results showing an insignificant effect for managerial support combined with similar findings from previous TAM studies imply that this construct within TAM is not applicable in the professional context, specifically, for physicians.

The development of ACMS is still in the initial stage, and this study develops a unified model by integrating TAM, SN, IN and MS to understand the physician's intention to accept and adopt ACMS. This study indicates that ACMS is a feasible model to use to investigate physician choice. Through this model, key factors necessary for physicians to choose ACMS may be strengthened and improved in order to increase its use. From the physicians' perspective, this study proposed specific suggestions to improve the use of ACMS to achieve the following benefits.

For physicians, results can be used to improve home healthcare service, by understanding the physician's intention of using ACMS; technology developers may create new products for physicians and patients, such as user-friendly interfaces and better equipment. For policy makers, this study provides important factors that users consider in choosing ACMS. These factors may be improved and strengthened so that the physicians can understand and identify with the core value of ACMS. With the current pressures of costly medical expenditures and expensive healthcare, this study may help to find an effective policy guideline and strategy to reduce medical costs and save medical resources. Applying findings in hospitals can accelerate the development of ACMS and effectively integrate the information, communication, and technology industries in order to improve patients' lives.

By providing a better understanding of physician technology acceptance, this model will inform health care managers about barriers that make physicians hesitant to embrace new technologies designed to increase efficiency and improve quality of ACMS. The results reveal that physicians' behavioral intention has the greatest effect on their attitude, followed by PU, MS, SN, PEOU, and IN. This means that it is essential for medical institutions to strengthen physicians' attitudes by advocating the system's benefits and operating convenience.

Our study results led to two recommendations. First, a modified version of TAM would be very useful in assessing physicians' attitudes toward acceptance of ACMS applications. Second, additional research is needed to examine the effects of physicians' characteristics on e-health adoption and evaluation of a mobile system, and these results can then be compared with those of physicians across specialties, disciplines, geographic boundaries, and cultures. In addition, future studies 
should look at the effects of "hands-on" educational interventions on the on basic TAM relationships.

\section{REFERENCES}

[1] Lin, S. P. and Yang, H. Y. (2009) Exploring key factors in the choice of e-health using an asthma care mobile service model. Telemedicine and e-Health, 15, 884-890.

[2] Liu, W.T., Huang, C.D., Wang, C.H., Lee, K.Y., Lin, S.M. and Kuo, H.P (2011) A mobile telephone-based interactive self-care system improves asthma control. European Respiratory Journal, 37, 310-317. doi:10.1183/09031936.00000810

[3] Tulu, B, Burkhard, R.J. and Horan, T. A. (2006) Information systems and health care: A user-driven approach to personal health records. Communications of the Association for Information Systems, 18, 641-656.

[4] Davis, F.D. (1989) Perceived usefulness, perceived ease of use, and user acceptance of information technology. MIS Quarterly, 13, 319-340. doi:10.2307/249008

[5] Lin, S. P. (2011) Determinants of adoption of mobile healthcare service. International Journal of Mobile Communications, 9, 298-315. doi:10.1504/IJMC.2011.040608

[6] Bhatti, T. (2007) Exploring factors influencing the adoption of mobile commerce. Journal of Internet Banking and Commerce, 12, 1-13.

[7] Venkatesh, V. and Davis, F.D. (2000) A theoretical extension of the technology acceptance model: Four longitudinal field studies. Management Science, 46, 186-204. doi: $10.1287 / \mathrm{mnsc}$.46.2.186.11926

[8] Yang, K.C.C. (2005) Exploring factors affecting the adoption of mobile commerce in Singapore. Telematics and Informatics, 22, 257-277. doi:10.1016/j.tele.2004.11.003

[9] McFarland, D.J. and Hamilton, D. (2006) Adding contextual specificity to the technology acceptance model. Computers in Human Behavior, 22, 427-447. doi:10.1016/j.chb.2004.09.009

[10] Yi, M.Y., Jackson, J.D., Park, J.S. and Probst, J.C. (2006) Understanding information technology acceptance by individual professionals: Toward an integrative view. Information \& Management, 43, 350-363. doi:10.1016/i.im.2005.08.006

[11] Robinson, J.L., Marshall, G.W. and Stamps, M.B. (2005) Sales force use of technology: Antecedents to technology acceptance. Journal of Business Research, 58, 1623-1631. doi:10.1016/j.jbusres.2004.07.010

[12] Schepers J. and Wetzels, M. (2007) A meta-analysis of the technology acceptance model: Investigating subjective norm and moderation effects. Information \& Management, 44, 90-103. doi:10.1016/j.im.2006.10.007

[13] Hartwick, J. and Barki, H. (1994) Explaining the role of user participation in information system use. Management Science, 40, 440-465. doi:10.1287/mnsc.40.4.440

[14] Chau, C.P.A.U.L.K. and Hu, P.J.H. (2002) Investigating healthcare professionals' decisions to accept telemedicine technology: an empirical test of competing theories. Information \& Management, 39, 297-311.

[15] Schaper, L.K. and Pervan, G.P. (2007) ICT and OTs: A model of information and communication technology acceptance and utilisation by occupational therapists. International Journal of Medical Informatics, 76, 212-221.

[16] Wu, J.H., Wang, S.C. and Lin, L.M. (2007) Mobile computing acceptance factors in the healthcare industry: A structural equation model. International Journal of $\mathrm{Me}$ dical Informatics, 76, 66-77. doi:10.1016/j.ijmedinf.2006.06.006

[17] Hurt, H.T., Joseph, K. and Cook, C.D. (1977) Scales for the measurement of innovativeness. Human Communication Research, 4, 58-65. doi:10.1111/j.1468-2958.1977.tb00597.x

[18] Rice, T. H. and Labelle, R. J. (1989) Do physicians induce demand for medical services? Journal of Health Politics, Policy and Law, 14, 587-600. doi:10.1215/03616878-14-3-587

[19] Nunnally, J.C. (1978) Psychonometric theory. McGrawHill, New York.

[20] Bagozzi, R.P. and Yi, Y. (1988) On the evaluation of structural equation models. Journal of the Academy of Marketing Science, 16, 74-94. doi:10.1007/BF02723327

[21] Hair, J.F., Black, B., Babin, B., Anderson, R.E. and Tatham, R.L. (2006) Multivariate data analysis. Pearson Education Inc., Upper Saddle River.

[22] Richard, K. (2007) An empirical examination of patient-physician portal acceptance. European Journal of Information Systems, 16, 751-761. doi:10.1057/palgrave.ejis.3000719 